\title{
ACKNOWLEDGING DIVERSITY: THE NEED TO PROMOTE AFRICAN LANGUAGES
}

\section{Zubeida Desai}

Multilingualism has become fashionable. However, the complexity of the concept is not widely recognized. Multilingualism is best addressed by extending the use of African languages beyond the fourth year at school. However, it is possible that this could frustrate learning, since at present it is difficult to develop CALP abilities in the L2 via the L1, because of facts such as the low status of its speakers. Research should be done into the BICS and CALP abilities of the pupils concerned at std 4 and std 9 level to determine the factors which influence language proficiency.

Multilinguisme het ' $n$ modewoord geword, maar die kompleksiteit van die konsep word nie allerweë begryp nie. Die beste manier om multilinguisme aan te spreek is om die gebruik van Afrikatale te verleng tot na die vierde skooljaar. Dit is egter moontlik dat so ' $n$ stap leer kan belemmer, aangesien dit tans moeilik is om kognitiewelakademiese taalbevoegdheid deur middel van die eerste taal in die tweede taal te ontwikkel omrede faktore soos die lae status van sy sprekers. Die kognitiewe/akademiese taalbevoegdheid en basiese interpersoonlike kommunikasievaardighede van die betrokke leerlinge op st 4- en st 9-vlak behoort nagevors te word om vas te stel watter faktore taalbevoegdheid beinvloed.

\section{INTRODUCTION}

Over the last few years, probably since 1990 when schools falling under the former House of Assembly elected to become Model C schools, it has become fashionable to champion multilingualism. However, this term may be interpreted in a number of ways.

Two authoritative works on multilingualism in this country and in Africa generally that may be a useful means of providing direction. The first is a book edited by Fardon and Furniss titled African languages, development and the state. In their introduction to this book, the editors focus on a central language issue in Africa. They "question the way that the term "languages" has featured in considerations of African languages, development and the state, and shift attention from African languages to specific linguistic practices in contemporary Africa, ... as these emerge in situations of multilingualism" (Fardon \& Furniss 1994:3). For them multilingualism is a complex phenomenon requiring a redefinition of "lingua franca", so that it relates to languages rather than a language. They go on to describe, in metaphoric terms, "the contrast between boundaries (connoting exclusive and distinct phenomena) and frontiers (suggesting the interpenetration of phenomena)" (Fardon \& Furniss 1994: 3).

For them, "multilingualism is the African lingua franca" (Fardon \& Furniss 1994: 4). This point is highlighted in the following paragraph:

The African lingua franca might best be envisaged not as a single language but as a multilayered and partially connected language chain, that offers a choice of varieties and registers in the speaker's immediate environment, and a steadily diminishing set of options to be employed in more distant interactions, albeit a set that is always liable to be reconnected more densely to a new environment by rapid secondary language learning, or by the development of new language. [my emphasis] 
Sarah Slabbert, who has been involved in market-related research among black South Africans, comes to a similar conclusion. She writes:

We found effective multilingual communication to be not an ideal, but an everyday reality for millions of South Africans ...

The main emphasis in multilingual interaction is on the maximum accommodation of the hearer. Lingua francas were the exception.... We found that multilingual communication brings millions of South Africans of different language backgrounds and cultures together on a daily basis in such a way that they accommodate and respect each other (Slabbert 1994:7).

Both Slabbert (1994) and Fardon and Furniss (1994) make mention of the complexities of the language situation, particularly with regard to the development of textbooks. When it comes to the written word, there will have to be some consensus on a standard form, be it the standard form of a multilingual competence or that of a single variety. This is an illustration of what Fardon and Furniss describe as "steadily diminishing options".

\section{A CASE TO BE MADE}

In this paper I wish to argue that, in the South African context, multilingualism is best addressed by extending the use of African languages in formal education beyond the fourth year at school. Not only can recourse to the mother tongue facilitate learning for pupils, but it can also facilitate the learning of a second language.

The next part of this article

* makes the conceptual framework of the argument explicit

* outlines the linguistic/cognitive constructs drawn on

* contextualizes the discussion in the South Africa, and

* provides an outline of the proposed research methodology.

\section{CONCEPTUAL FRAMEWORK}

The axiom that it is best for a child to be taught through his/her mother tongue gained much ground through UNESCO's report (1953) on the use of vernacular language in education. This report asserted the right of all children to be educated in their mother tongue, a right that was vigorously supported by multicultural lobbies in the $60 \mathrm{~s}$ and the 70s. Now, almost forty years later, controversy continues over the practical difficulties of implementing such a right, and whether there can be a single language right for all situations (Cazden et al 1990).

However, such a debate has to be located within a broader sociolinguistic framework which takes into account factors such as

* the role of the mother tongue in the broader society

* attitudes to mother tongues and languages of wider communication, and

* language proficiencies of teachers

* materials available in different languages 
exposure to languages of wider communication, and

the political will to promote indigenous (in this case, African) languages.

The mother tongue is not always best as a language of learning. The merits or demerits of mother tongue education are dependent on the particular context in which learners find themselves.

As was established earlier (Fardon \& Furniss 1994, Slabbert 1994), the notion of "mother tongue" is not an unproblematic one in the South African context. The notion of mother tongue education does not necessarily apply neatly to any one of the nine languages designated as African languages. Many speakers of African languages speak a variety which may be described as a mixture of more than one language. Whilst a standard variety is accepted for the written form, it is often challenged in the spoken form. This continues to pose many problems for the speakers of these languages and for policy makers. One such problem is the lack of terminology, which has far reaching implications for education and the publishing process. Those who celebrate the many varieties in languages sometimes fail to take account of these implications.

\section{LINGUISTIC/COGNITIVE CONSTRUCTS}

In evaluating the arguments for or against the use of the mother tongue in formal education, proponents of either perspective have recourse to different linguistic/cognitive constructs. For the purpose of this article, the constructs that will be briefly considered are

* additive/subtractive bilingualism

* the threshold level hypothesis

* semilingualism

* the linguistic interdependence hypothesis

* basic interpersonal communication skills (BICS)

* cognitive/academic language proficiency (CALP).

Although, for the purpose of this study, these theories can be viewed as forming a cluster, each of these will be outlined, mainly in terms of Cummins $(1979,1980,1984)$.

The term additive bilingualism is used to refer to a situation where a second language is acquired "without any loss or weakening of the first language" (Makoni 1993). The St Lambert's immersion experiments in Canada in the 1970s are a good example of this.

Subtractive bilingualism, on the other hand, refers to a situation where the second language is acquired at the expense of the first. This usually happens in situations where the first language is not a dominant language and has a low status.

The threshold level hypothesis was first postulated by Cummins (1976) and Toukomaa \& Skutnabb-Kangas (1977). They suggest that research on cognition and bilingualism is best explained by "the idea of two thresholds" (Baker 1993: 136). The first threshold is a level for a child to reach to avoid the negative consequence of "bilingualism". The second threshold is a level required to experience the possible positive benefits of bilingualism. The threshold hypothesis assumes that the positive effects of bilingualism will only come into being once a child has attained a certain minimum level (threshold level) of competence in the L1 and the L2. However, the threshold cannot be defined in absolute terms; it is likely to vary according to the child's stage of cognitive 
development and the academic demands of different stages of schooling. As the curriculum content becomes more symbolic and requires more abstract formal operational thought processes, the child's "surface" L1 (and/or L2) must be translated into deeper levels of competence in the language. The development of adequate literacy skills are obviously crucial in this respect (Cummins 1979).

The term "semilingualism" has been used to describe what was referred to above as the "negative consequences of bilingualism". Hansegard (1968) cited in Martin-Jones \& Romaine (1986) originally used the term "halvsprakighet" to describe what he believed to be the less than complete linguistic skills of Finnish-Swedish bilingual Finns in Tornedal. The term "semilingualism" re-emerged in the last two decades of research on the language education of ethnic minority children whose parents are of immigrant origin. In Sweden, for instance, it was used with reference to the language skills of the children of Finnish migrant workers

Researchers in Canada,- (Cummins 1979), for instance, also adopted the term. The central concern, according to Cummins is

why does a home-school language switch result in high levels of functional bilingualism and academic achievement in middle class majority language children ... yet lead to inadequate command of both first (L1) and second (L2) languages and poor academic achievement in many minority language children? (Cummins 1979: 222).

Cummins has subsequently dropped what proved to be a controversial term. Those interested in the debate are referred to the articles by Edelsky et al. (1983), Martin-Jones and Romaine (1986) and Tosi (1989).

Cummins (1979) argues that the findings of several research studies suggest that maintenance of L 1 skills can lead have cognitive benefits for minority language children. It is useful to note that such research findings are evident in situations as varied as the USA and Nigeria. Two significant studies are the work done with Navaho speakers at Rock Point (cf Holm \& Holm 1990) and the Six Year Primary Project conducted with Yoruba speakers in Nigeria (cf Babs Fafunwa 1978).

What is important about the threshold hypothesis is the notion that the benefits of bilingualism are not automatic. Benefits emerge under certain conditions, and in a particular context (Cummins 1979). As Fishman (1977) quoted in Cummins (1979: 229) warns, "bilingualism should not be spuriously oversold now as it was spuriously undersold (or written off) in the past".

This brings us to the linguistic interdependence hypothesis which was espoused by Cummins (1979). This hypothesis states that the development of competence in a L2 is partially a function of the type of competence already developed in the L1 at the time when intensive exposure to the L2 begins. In other words, the acquisition of L 2 is influenced by the learner's level of development in the L1. Cummins suggests that differences in the way in which children's L 1 has been developed by their linguistic experience prior to school contribute to the differential outcomes of a home-school language switch in minority and majority language situations. This could be one of the factors accounting for the success of the Canadian immersion programmes (cf the St Lambert experiment of the 1960s). However, as Cummins points out, there has not been much attempt to determine which aspects of L1 development interact with the medium of instruction.

An important aspect of academic work the ability to extract information efficiently from the printed text. Subsequent educational progress largely depends upon how well this task is accomplished. Fluent reading skills are therefore quite crucial. As Smith (1971) points out, such skills require that the reader's knowledge of language is used to make 
inferences or predictions about information in the text. The child ability to process language which is decontextualised, normally part of L1 development, is likely to influence his or her ability to read successfully.

In assessing learners' proficiency in a language, both surface fluency, what Cummins (1980) calls basic interpersonal communication skills (BICS) and academic language competence, referred to by Cummins as cognitive/academic language proficiency (CALP), have to be taken into account. Cummins distinguishes between the two by defining CAL.P as

those aspects of language proficiency which are closely related to the development of literacy skills in L1 and L2. ... BICS in L1 such as accent, oral fluency, and sociolinguistic competence may be independent of CALP for a variety of reasons...(Cummins 1980:177).

In a school context, this would refer to a level and a type of proficiency necessary for carrying out a specific task.

Cummins goes on to argue that

if the purpose of language proficiency assessment is to assign bilingual children to classes taught through the language in which they are most capable of learning, it is essential that these measures assess CALP. Thus, if natural communication tasks do not assess CALP, their relevance to the educational performance of bilingual children under linguistically different conditions can be questioned (Cummins 1980: 177).

CALP would therefore presumably relate to the kind of proficiency needed to use a language as a medium of instruction successfully. This is a point taken up by Macdonald (1993) in her writing on black primary education in South Africa. If the interdependence hypothesis is valid, the L1 and L2 CALP should relate strongly to each other. Cummins does, however, imply that the transfer of CALP abilities from the L1 to the L2 (or vice versa) is not necessarily automatic. Factors such as motivation and attitudes can have a negative effect on such transfer (1979).

There are also certain aspects of language proficiency more effectively handled by older learners than by younger children, or vice versa. The study by Ramsey and Wright in the 1970 s of over 1200 immigrant students in the Toronto school system who were learning English as a second language (cited in Cummins 1980) shows that older L2 learners, whose L1 CALP is better developed display a higher level of CALP than younger learners whose L1 CALP is not very developed.

It is important to bear in mind that for the full complexity of the linguistic situation to be taken into account, these theories have to be integrated within a more comprehensive sociolinguistic framework, one which subsumes individual variables but also looks at socio-political variables. The sociolinguistic situation in which the majority of African learners find themselves is one in which they are at a disadvantage.

Present language in education policy privileges those whose home language is either Afrikaans or English by enabling them to be taught through the medium of their first language throughout their years at school, and beyond. This is a right that, in practice, is denied speakers of the major African languages(Desai 1994: 25).

African children, as a general rule, begin their schooling in their home language, which remains the medium of instruction through the fourth year of schooling (Std 2). English (and Afrikaans, in some situations) is studied as a subject. In the fifth year of schooling there is a shift in medium of instruction - in theory to either English or Afrikaans but in 
practice virtually always to English. It might be argued that the June 1991 amendment to the 1979 Education and Training Act allows speakers of African languages the same choice enjoyed by English and Afrikaans speakers. This amendment transfers to parents the right to decide, in consultation with the Minister, which language should be used as medium of instruction for their children and at what level. But since there is no infrastructure in terms of teacher training or materials development to back the amendment meaningless in practice. It seems that the overwhelming effect of the present language in education policy for African learners is that it is "deeply disabling" (French 1990).

More research is imperative to monitor the effects of the present policy and to inform policy-making. The Threshold Project led by Macdonald represents a beginning.

The picture that does emerge from the documentation available is as follows: most learners have difficulty in coping with the demands of using English as a medium in the primary school (Macdonald 1990). Such difficulties are usually carried into high school and tertiary institutions. Even those learners who display a level of proficiency at the BICS level have serious difficulties with reading and writing tasks. Generally, the learning experience is a frustrating one for both learners and teachers. Many teachers lack the necessary proficiency and it is not uncommon for teachers to switch to the mother tongue while teaching. Such codeswitching, however, is not officially sanctioned. However, it may in fact constitute good practice. What seems to be emerging quite clearly though is a disjuncture between policy on paper and policy in practice. The depth of the problem has been documented quite ably by Macdonald $(1990,1993)$. There is, however, another disjuncture that is not often commented on. When discussing language in education policy many teachers (and parents and learners) might argue for the use of English as a medium without considering what is currently happening in the classrooms. Teachers who codeswitch all the time would very seldom admit to it. If we want to build on existing practice, then this disjuncture between professed attitudes and practice needs to be addressed.

This is the context for extending the use of African languages in formal education. Although much has been written about language difficulties experienced by African children, such writing has tended to identify the problem as poor proficiency in English and ways in which to remedy this. In the South African sociolinguistic situation in South Africa, learners' and teachers' actual linguistic strengths, that is their ability to speak proficiently one or more African language, must be utilised. The linguistic interdependence hypothesis which argues that there is a link between L1 and L2 development, suggests that it would make pedagogic sense to extend proficiency at the CALP level in the Ll of learners and teachers before exposing learners to English as a medium of instruction.

However, the inadequate development of African languages at present militates against the possibility of developing CALP abilities in the L2 via the L1. This inadequate development may be attributed to a number of factors. I mention but two: the low status of its speakers (generally speaking), and the limited human and material resources available for developing these languages.

In popular discussions of political policy, the role that different languages should play in education remains a highly contentious issue. At the time of writing, the situation remains a fluid one, despite the fact that the interim constitution allows for eleven official language which include the nine major African languages. There is a real danger that such recognition could operate at a symbolic level only if issues of implementation are not addressed. There is a belief in some quarters that in order to improve proficiency in English (L2) we need to introduce more English sooner - the maximum exposure hypothesis. I doubt the success of such an initiative for the majority of African learners there simply are not enough English-speaking teachers. Although I am aware that, technologically, there is the potential for enriching the acquisitionally-poor environment 
for English through the use of public media, the chances of it being realised in the immediate future are not very encouraging.

\section{OUTLINE OF RESEARCH METHODOLOGY}

The challenge, first though is translating theory into practical concerns rooted in present socio-political reality. There is a very important role for those who wish to fight shy away of the political, and instead to provide the necessary evidence to policy makers and teachers as to what is likely to facilitate rather than frustrate learning.

In this final section, the design of research aimed at investigating the case for extending the use of African language in formal education is outlined.

For the sake of convenience, the subjects will be selected from four Department of Education and Training (DET) classes in the Western Cape. Two of the classes will be Std 4 pupils (approximately 12 year olds) and two Std 9 pupils (approximately 17 year olds). The Std 4 pupils would have been taught in an African language fairly recently (at Std 2 level) whilst the Std 9 pupils would have (officially) had English as a medium of instruction for at least six years. The subjects would have been chosen in relation to the time of the switch to the L2 (English). The switch to English generally happens in Std 3 at present. Std 4 is therefore soon after the switch to English, whilst Std 9 is long after the switch.

My suspicions are that

the Std 4 pupils' CALP abilities in the African language would be better than their CALP abilities in English.

the CALP abilities of the Std 4 pupils in the African language would be better than that of the Std 9 pupils, with due account being taken of their age; and

the CALP abilities in English of the Std 9 pupils would not be sufficiently high to meet the academic demands placed on them.

The study will be a combination of a cross-sectional (Std 4 and Std 9) and a longitudinal (over 12 months) design.

\section{ELICITATION INSTRUMENTS:}

Data elicited would fall into two categories: focussed data and contextual data.

The focussed data would be drawn from tasks designed to determine abilities, at both the BICS and CALP levels. I am currently exploring the use of the TELS (Teaching English Language Skills) material. Tasks used for assessing proficiency in English would be translated into the relevant African language as well.

Apart from the need to compile a profile pupils' proficiencies, the purpose of using standardised tasks such as the TELS material is that it makes possible comparisons with other studies involving tasks such as cloze and picture description tasks. These tasks would have to be adapted partially to suit the "cultural ecology" of the students. The focussed data would also involve tasks looking at cognitive abilities.

Contextual data drawn from ethnographic studies would complement the focussed data. This data would make it possible to compile a profile of languages and speakers of those languages to assess the degree of multilingualism. It would also supply social data on the subjects. There is likely to be a correlation between the socio-economic context in which the subjects find themselves and their language proficiency, mediated by individual differences such as motivation and aptitude. 


\section{BIBLIOGRAPHY}

BABS FUWANA, A. 1978. Education in Lesotho: A New Look. In How Can Schools Best Help the Children Learn? Maseru: The Kingdom of Lesotho, Ministry of Education.

BAKER, C. 1993. Foundations of Bilingual Education and Bilingualism. Clevedon: Multilingual Matters.

CAZDEN, C. SNOW, C. AND HEISE-BAIGORRIA, C. 1990. Language planning in preschool education with "annotated bibliography". Massachusetts: Harvard Graduate School of Education.

CUMMINS, J. 1976. The influence of bilingualism on cognitive growth: a synthesis of research findings and explanatory hypotheses. Working Papers on Bilingualism, Vol 9: 1-43.

CUMMINS, J. 1979 Linguistic interdependence and the educational development of bilingual children in Review of Educational Research, Vol. 49, No 2 pp 222-251.

CUMMINS, J. 1980 The cross-lingual dimensions of language proficiency: Implications for bilingual education and the optimal age issue. In TESOL Quarterly Vol. 14, No. 2.

CUMMINS, J. 1984. Wanted: A theoretical framework for relating language proficiency to academic achievement among bilingual students in Rivera, C.: Language Proficiency and Academic Achievement. Clevedon: Multilingual Matters.

CUMMINS, J. AND SWAIN, M. 1986. Bilingualism in Education. London: Longman.

DESAI, Z. 1994. A "deeply disabling" policy. In DSA in Depth. Epping: Creda Press.

EDELSKY, C. ET AL. 1983. Semilingualism and language deficit. In Applied Linguistics Vol 4 No. 1.

FARDON, R. \& FURNISS, G. (EDS). 1994. African languages, development and the state. Routledge: London \& New York.

FISHMAN, JA. 1977 The social science perspective. In Bilingual Education: Current perspectives. Vol. 1 Social Science. Arlington, Va.

FRENCH, E. 1990. English: medium of instruction or enemy of instruction? In Language Projects Review, Vol. 5 No. 3.

GORMAN, TP. 1974. The development of language policy in Kenya with particular reference to the educational system. In Whitel, W.H. (ed.). Language in Kenya. Nairobi: Oxford University Press.

HOLM, Agnes AND Wayne. 1990 Rock Point, A Navajo Way to go to school: a valediction. In The Anals Vol. 508.

MACDONALD, CA. 1990. Crossing the Threshold into Standard Three in Black Education: The Consolidated Main Report of the Threshold Project. Pretoria: HSRC. 
MACDONALD, CA. 1993. Towards a new primary curriculum in South Africa. Pretoria: HSRC.

MAKONI, S. 1993. Mother-tongue education: a literature review and proposed research design. In South African Journal of African Language, Vol. 13(3).

MARTIN-JONES, M. AND ROMAINE, S. (1986) Semilingualism: A Half-baked Theory of Communicative Competence. In Applied Linguistics, Vol. 7 No. 1.

NEPI (1992) Language. Cape Town: OUP.

SLABBERT, S. 1994. IsiSoweto: Ek slaan al die tale. In Bua, Vol. 9(1) 4-7.

SMITH, F. 1971. Understanding reading. New York: Holt, Rinehart and Winston.

TELS Material 1987. Hampshire: Macmillan Education.

TOSI, A. 1989. Bilingual Education. In Annual Review of Applied Linguistics 10, 103121 CUP.

TOUKOMAA, P. AND SKUTNABB-KANGAS, T. 1977. The intensive teaching of the mother tongue to migrant children of pre-school age and children in the lower level of comprehensive school. Helsinki: Finnish National Commission for UNESCO. 